\title{
Modelling multiple threats to water security in the Peruvian Amazon using the WaterWorld policy support system
}

\author{
A. J. J. van Soesbergen and M. Mulligan \\ Earth and Environmental Dynamics Research Group, Department of Geography, King's College London, \\ Strand, London, WC2R 2LS, UK
}

Correspondence to: A. J. J. van Soesbergen (arnout.van_soesbergen@kcl.ac.uk)

Received: 31 May 2013 - Published in Earth Syst. Dynam. Discuss.: 27 June 2013

Revised: 14 December 2013 - Accepted: 26 December 2013 - Published: 31 January 2014

\begin{abstract}
This paper describes the application of WaterWorld (www.policysupport.org/waterworld) to the Peruvian Amazon, an area that is increasingly under pressure from deforestation and water pollution as a result of population growth, rural-to-urban migration and oil and gas extraction, potentially impacting both water quantity and water quality. By applying single and combined plausible scenarios of climate change, deforestation around existing and planned roads, population growth and rural-urban migration, mining and oil and gas exploitation, we explore the potential combined impacts of these multiple changes on water resources in the Peruvian Amazon.
\end{abstract}

\section{Introduction}

Hydrologic systems are subject to changes that may be natural, such as climatic, ecological and earth surface changes, or human-induced (i.e. land use change, infrastructural works, etc.). The interconnectedness of water with biotic, physical and social systems and associated complexity and nonstationarity constitutes a significant challenge to modelling these hydrological systems (Gupta et al., 2000) especially for impacts projection. The feedbacks between water and human society are particularly difficult to understand (Rockström et al., 2009; Gleick and Palaniappan, 2010). To understand water management problems in such complicated systems therefore requires the development of models and tools that are able to capture the underlying physical processes of the natural system but also incorporate interactions and feedbacks with human systems (Wagener et al., 2010). The WaterWorld policy support system (Mulligan, 2013b) addresses this challenge by providing users with the possibility of assessing the impacts of a range of either natural or humaninduced scenarios on the calculated baseline hydrology. Moreover, it provides scientific information and scenario analysis to users who do not have technical or hydrological capacity, thus allowing for a more open, inclusive and participatory approach to hydrological impacts modelling. In this paper we apply WaterWorld to the Peruvian Amazon, an area that is increasingly under pressure from deforestation and pollution as a result of population growth, rural to urban migration and oil and gas (o\&g) extraction, potentially impacting water quantity and water quality. We analyse the impacts of these scenarios applied individually and then in combination to understand interactions and implications for water security. See Mulligan et al. (2013) for a similar analysis for the entire Amazon Basin. User interaction with the model is not explored in the present study; however the use of this model with stakeholders is an integral part of the CGIAR Challenge Programme on Water and Food project COMPANDES under which some of the WaterWorld development was carried out.

\subsection{WaterWorld}

WaterWorld is a fully distributed, process-based hydrological model that utilises remotely sensed and globally available data sets for application to supporting hydrological analysis and decision-making, and is especially useful in un-gauged and/or data-poor environments. Where users have local data these can be uploaded and used in WaterWorld analysis, but where they do not, simulations are still possible with global data sets delivered with the model. The so-called policy support system is accessible through a web browser (and runs on a server, requiring no local installation) and is available at 
www.policysupport.org/waterworld. The model (v2.x) currently runs simulations on either 10-degree square tiles at $1 \mathrm{~km}^{2}$ resolution or 1-degree square tiles at 1 ha resolution. It simulates a hydrological baseline as a mean for the period 1950-2000 and can be used to calculate hydrological scenarios of climate change, land use change, land management options, impacts of extractives (oil \& gas and mining) and impacts of changes in population and demography as well as a combination of these. As well as modelling water quantity (water balance cumulated downstream as runoff), WaterWorld generates an indicator of the potential level of contamination of water by human activities. This so-called human footprint on water quality index (HF; Mulligan, 2009) is an index of the extent to which water is affected by upstream and local human activities. Water balance in the model is calculated as wind-driven rainfall plus fog inputs minus actual evapotranspiration according to climate and remotely sensed vegetation cover. A snow and ice module based on Walter et al. (2005) simulates the accumulation of snow in relation to precipitation and temperature and its melting to simulate meltwater contributions. Water balance is cumulated downstream along a terrain-derived flow network. WaterWorld simulates the land component of the hydrological cycle, not the atmospheric component, so it does not attempt to simulate changes to rainfall on the basis of changed evapotranspiration, though the user is free to apply such effects as "stacked" scenarios. Dams in WaterWorld have two effects: first their associated reservoir evaporates at free water rates rather than those associated with (vegetated) land, and second they act as a linear store for water and sediment from upstream. The storage capacity is shared between water and sediment and is defined according to an empirically derived relationship of reservoir volume from reservoir surface area. Baseline dams are represented by those mapped in the global database of dams (Mulligan et al., 2009). However we do not model water allocation from dams in WaterWorld because WaterWorld dynamically links to the WEAP model (Yates et al., 2005) for such analyses. We have not used the WaterWorld-WEAP link in this study since no dam-building scenarios are investigated here.

The model is "self-parameterising" in the sense that all data required for model application anywhere in the world are provided with the model. However, if users have better data than those provided with WaterWorld, it is possible to upload these as GIS files. Results can be viewed visually within the web browser or downloaded as GIS maps. The model's equations and processes are described in more detail in Mulligan and Burke (2005) and Mulligan (2013b). Model testing and validation has been described in Mulligan and Burke (2005), Bruijnzeel et al. (2011) and Van Soesbergen (2013). The model is not routinely calibrated to observed flows as it is designed for hydrological scenario analysis and use in un-gauged basins. Calibration is inappropriate under these circumstances (Sivapalan et al., 2003). Moreover, it is assumed that if a physically based model is capable of reproducing current conditions based only on physical relationships, it is likely it would continue to do so under scenario conditions since the physical relationships would remain the same (Mulligan, 2013b). Since this analysis focuses on understanding the physical relationships between drivers and outcomes through hydrological processes, calibration of parameters to current conditions would negatively affect the physical basis of WaterWorld and hence the likelihood that the calibrated parameters would be representative under scenario conditions.

\subsection{Water security}

Increases in water demand, along with uncertain future climate change and potential changes in frequency and intensity of floods and droughts, means many areas around the world may face a decrease in water security into the future (Postel and Wolf, 2001; Gleick and Palaniappan, 2010), with as much as $80 \%$ of the world's population estimated to be affected by high-level water security risk (Vörösmarty et al., 2010; Bakker, 2012). Low-income nations are likely to be more impacted (Hope et al., 2012) but also have the least ability to mitigate these risks as they sometimes lack the capacity and resources to invest in water resources management infrastructure and institutions. There are many definitions of water security currently employed in academic and policy literature (Cook and Bakker, 2012). In the context of this paper, we define water security as the capacity of a population to ensure sustained access to water in terms of water quantity and quality (Mulligan et al., 2013). The analysis therefore focuses on water stress, defined as the ratio of water use (demand) to availability (supply), and water quality, based on the human footprint on water quality index.

\section{Study area}

The study area comprises the northern two thirds of the Peruvian Amazon-Andes Basin (PAB). The region covers an area of $611653 \mathrm{~km}^{2}$ and is geographically located within the coordinates of latitude $0^{\circ} \mathrm{N}$ to $10^{\circ} \mathrm{S}$, and $80^{\circ} \mathrm{W}$ to $70^{\circ} \mathrm{W}$ of longitude, which is the extent of the relevant WaterWorld $1 \mathrm{~km}^{2}$ resolution analysis tile (Fig. 1), masked to the PAB. Elevation in the region ranges from more than $6050 \mathrm{~m}$ above mean sea level in the eastern Andes to less than $46 \mathrm{~m}$ a.m.s.l. in the Amazon rainforest. Mean annual rainfall in the study area (based on WorldClim, Hijmans et al., 2005) is approximately $2100 \mathrm{~mm}$ with much higher precipitation over the tropical rainforest and much lower precipitation in the Andes. Simulated annual total actual evapotranspiration averaged over the study area is approximately $780 \mathrm{~mm}$. According to the MODIS vegetation continuous field (VCF) maps produced by Hansen et al. (2006) tree cover makes up $70 \%$ of the region, nearly all of it concentrated in the low-lying tropical Amazon. MODIS VCF herbaceous 


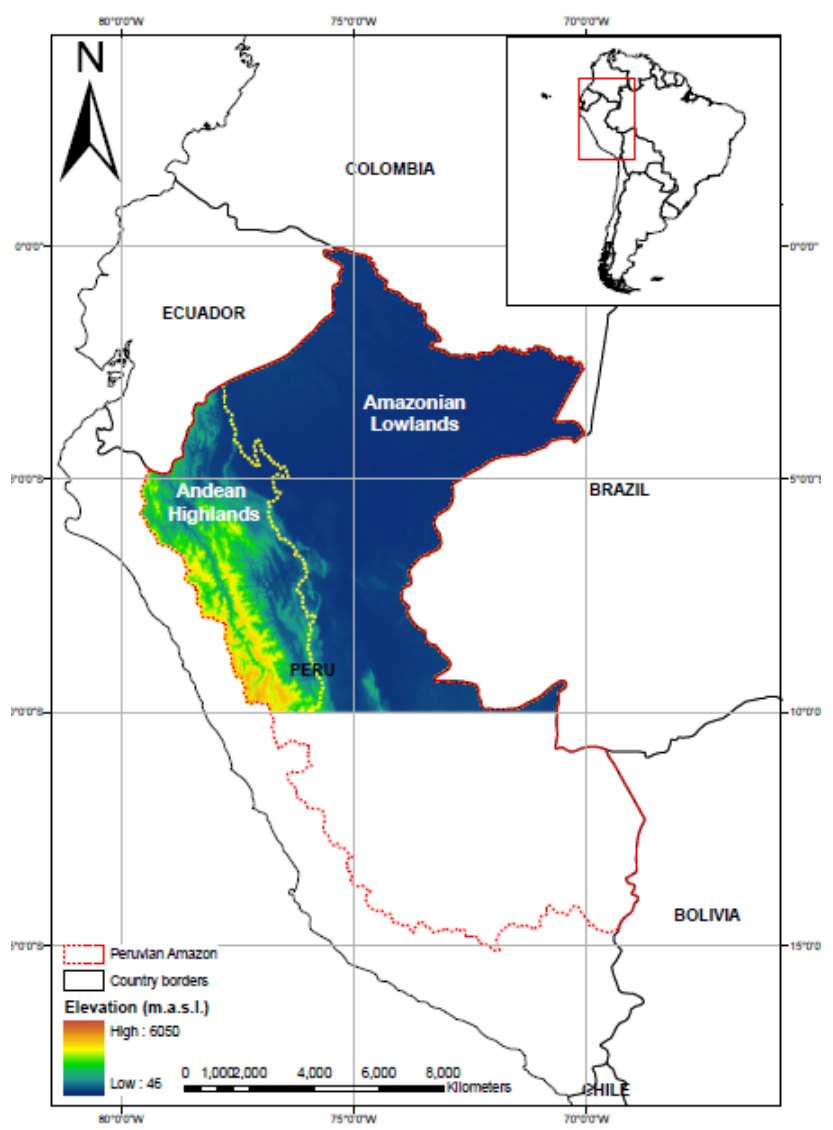

Fig. 1. Study area, extent of coverage of the Peruvian Amazon Basin and elevation in the region.

cover (which is mostly agriculture) constitutes $28 \%$, and it is mainly found at higher elevations in the Andes and along river valleys. Population in the area is around 10 million, with the highest population density found towards the west of the study area in the Andean subbasins, with the exception of the subbasin containing the city of Iquitos in the heart of the rainforest.

\subsection{Threats to water security in the Peruvian Amazon}

\subsubsection{Deforestation}

Deforestation rates in the study area averaged around 540 square kilometres per year between 2004 and 2011 according to Terra-i data (www.terra-i.org). Most of this change is the result of land conversion to agriculture near settlements and river valleys where there is good access through roads and also accessibility to markets. However, in more recent years there has been a surge in deforestation associated with gold mining (Swenson et al., 2011). Land use practices affect the annual and seasonal supply of freshwater through changes in the surface water balance and the partitioning of precipitation into evapotranspiration, surface runoff and subsurface flow
(Marengo, 2006), with decreases in forest cover leading to reduced evapotranspiration and increased water balance. The impact on runoff depends on the land use and management that replaces forest cover. Moreover, conversion of tropical forest to agriculture can lead to increased water pollution as a result of increased soil erosion and inputs of manures, pesticides, herbicides and fertilisers.

\subsubsection{Mining and oil and gas exploitation}

Mining activities and oil and gas production are economically important for Peru but can also have significant impacts on water security both through their use of water and their contamination of downstream water resources. Small-scale artisanal gold mining is a significant source of mercury pollution to surface waters (Swenson et al., 2011), while oil extraction is responsible for many oil spills and the release of untreated wastes into the environment (Napolitano and Ryan, 2007; Orta-Martínez et al., 2007). These extractive activities can also be a driver of extensive forest degradation through the development of infrastructure such as access roads. The wave of development and deforestation that follows mining and oil can have impacts on water quality and quantity. With nearly fifty percent of the Peruvian Amazon under oil and gas concessions in recent years (Finer and Orta Martinez, 2010) this is potentially a significant threat to the environment and water security.

\subsubsection{Climate change}

Climate change constitutes a significant compounding factor to water security as it potentially alters hydrological variability and the occurrence and frequency of extremes. Future changes in climate are extremely hard to predict, particularly for precipitation, which is fundamental to water security. In the Peruvian Amazon, a slight positive trend in temperature $\left(+0.09^{\circ} \mathrm{C}\right)$ has been shown between 1965 and 2007, but no discernable trend for precipitation (Casimiro et al., 2012). Projections based on climate models generally predict an increase in temperature by around $2{ }^{\circ} \mathrm{C}$ for the period 2000 2050 with precipitation projections highly spatially variable, with some areas decreasing and others increasing but overall showing a slight increase in precipitation (Casimiro et al., 2011; Guimberteau et al., 2013).

\subsubsection{Population growth and urbanisation}

Population growth affects water security as it leads to an increase in demand both directly for domestic supply as well as indirectly for industrial and agricultural water use. Immigration and settlement into the Peruvian Amazon have been accelerated in recent decades, partly due to the rise in extractive industry, with population growth rates of between 5 and $7 \%$ (Cardozo, 2011; Perz et al., 2010). The growing urban population is a driver for deforestation as a result of more infrastructure development (Weinhold and Reis, 2001; 
DeFries et al., 2010) and is also a cause of water pollution due to increased domestic sewage that generally leaves the cities in an untreated state (Braga et al., 2011).

\section{Methodology}

\subsection{WaterWorld water security metrics}

WaterWorld produces some 60 mapped output variables, 20 of which are also produced on a monthly basis (see Mulligan, 2013a; Mulligan et al., 2013). These outputs include the main hydrological outputs such as precipitation corrected for wind-driven effects, actual evapotranspiration and its cumulation downstream as runoff but also output generated by the wash soil erosion model (based on Thornes, 1990) and snowfall and melt water production produced by the snow and ice energy-balance model component (based on Walter et al., 2005). In order to assess impacts of scenarios for change on water security, we will use the WaterWorld water stress index which calculates water supply as the simulated water balance (i.e. after evaporative water use) and demand given as population multiplied by a user-defined per capita domestic and industrial demand (set here as $47 \mathrm{~m}^{3} \mathrm{yr}^{-1}$, or $130 \mathrm{Lday}^{-1}$ ). Supply and demand are calculated for each month. Agricultural demand is incorporated in the water balance since the water balance includes actual evapotranspiration from the present land cover and use (thus including the effects of irrigation). The water stress index is the percent of nonagricultural (blue water) demand not supplied in months at which supply is less than demand averaged for all months of the year. This is thus a cumulative index of water stress for each month and assumes no storage or surpluses in one month that might offset the lack of supply in the next, for example by reservoirs or groundwater stores. The metric is thus a measure of climatic and hydrological water stress, seasonally and annually, in the absence of infrastructural water management measures such as storage by dams and groundwater abstraction. Groundwater resources may act as a temporary buffer against water insecurity in the short term, but they cannot resolve insecurity in the long term (which is the focus of the WaterWorld security measure) since groundwater resources are ultimately controlled by the water balance. If water balance decreases, then groundwater reserves will also decrease in the long term. As well as water quantity, water quality is fundamental to water security since it determines the quantity available for a particular purpose (such as irrigation, domestic use etc.). Poor-quality water may be unusable for some purposes and bring with it risks of health insecurity. Water quality is very difficult to measure at policyrelevant scales since it cannot be remotely sensed per se. Thus, WaterWorld uses an index of the extent to which water is affected by human activities: the so-called human footprint on water quality index (HF, Mulligan, 2009). The HF essentially assumes that if rainfall falls on land that has low human impact then it will generate clean runoff, whereas if it falls on human land uses that may form point (mines, oil wells, roads, urban) or non-point (unprotected cropland and pasture) contaminant sources then the runoff generated is not clean (i.e. has a human footprint). The HF index (\%) at a point is thus the proportion of water at that point that fell as rainfall on upstream human-impacted areas and is an indicator of the potential level of contamination of water. All land covers are assumed to have the same unit impact, though users can change this if there is reason to believe that particular areas of cropland for example have a higher or lower pollutant release than others. The impacts on water quality are thus the magnitude and distributions of human land uses upstream in relation to where the rainfall falls.

\subsection{Scenarios}

In order to assess the impacts on water security by the threats described above for the Peruvian Amazon, we used the WaterWorld policy exercises tool to generate scenarios for each individual threat as well as a combination of these. These scenarios were then run in WaterWorld to examine the changes in water stress index and human footprint on water quality.

\subsubsection{Deforestation}

To examine the impacts of a scenario for land use change on elements of water security, the WaterWorld land use change model (Mulligan et al., 2013) was applied, which works on the basis of projecting recent rates of deforestation based on rates of land use change (for the last $8 \mathrm{yr}$ ) from Terrai data (vegetation loss) as a mean per regional administrative boundary continued into the future, deforesting areas with greatest current accessibility to major towns and closest to the existing deforestation fronts first. Land cover in the model is represented as a fractional cover of trees, herbaceous vegetation and bare ground in each $1 \mathrm{~km}$ pixel based on MODIS VCF (Hansen et al., 2006) alongside an indication of land use (cropping, grazing, mining, urban, protected areas) based on Ramankutty et al. (2008), IUCN and UNEP (2009) respectively. In the scenario applied, recent rates of deforestation were projected forward by $40 \mathrm{yr}$ to 2050 with protected areas ineffective at halting deforestation. Current forest cover was converted to a grazing use with a tree, herb and bare cover of 5, 90 and $5 \%$ respectively and an intensity of use of 1.0 (the standard, indicating low input, eco-efficient methods such as reduced tillage and low-input methods not used). Figure $2 \mathrm{a}$ and $\mathrm{b}$ show the baseline and scenario tree cover in percentage by pixel for the study area, and Fig. 3a shows the change in tree cover by major subbasin. 

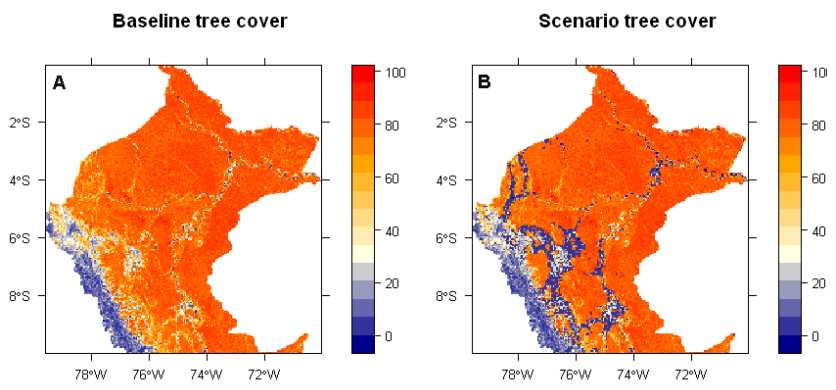

Fig. 2. (a) Baseline tree cover for study region based on MODIS VCF (Hansen et al., 2006); (b) scenario tree cover generated by WaterWorld land use change scenario generator.

\subsubsection{Mining in $10 \%$ of concession}

Within the study area, some $18000 \mathrm{~km}^{2}$, or $2.5 \%$, currently has a concession for open pit mining (Mulligan, 2011), nearly all of these are located along the western border of the basin in the Andes. It is difficult to predict how many of these concession areas will actually be developed into mining activities. However, continuing global demand for minerals and recent non-linear increase in mining area in the Peruvian Amazon indicate strong growth in the extractive industry in the region (Bebbington and Bury, 2008; Swenson et al., 2011). We chose to simulate a scenario whereby a conservative $10 \%$ of these concessions is turned into active mines, which means any vegetation cover is replaced by bare ground and the mining area expands to create an increase in point contaminant sources for the human footprint index. Figure $3 \mathrm{~b}$ shows the increase in number of mines by subbasin.

\subsubsection{Oil and Gas in $1 \%$ of the concession}

According to the WaterWorld oil and gas concessions data set (Mulligan, 2011), currently around $500000 \mathrm{~km}^{2}$, or $70 \%$, of the study area is under oil and gas concessions. Similar to the scenario for mining, a scenario whereby $1 \%$ of land in these concessions gets converted to oil production sites was implemented in the model (Fig. 3c). The actual conversion will depend upon the quantity and quality of oil reserves found and the price of oil and costs of production and transport. However, $1 \%$ is broadly similar to the occupancy of concessions in nearby Ecuador (Zuritha-Arthos and Mulligan, 2013), which has a much longer history of exploration and production and is thus a reasonable scenario of development.

\subsubsection{Climate change}

To examine the likely impacts of projected climate change, which can exacerbate or cancel out water security risks, WaterWorld was run with a climate change projection. We chose the SRES A2A scenario (Nakicenovic et al., 2000), representing high growth and a global $3.5^{\circ} \mathrm{C}$ warming (relative to 2000 ) by 2100 , although other IPCC climate change scenarios are also available from WaterWorld (Mulligan, 2013b). Rather than running the model with the projections of a single global climate model (GCM), we ran it with an ensemble mean scenario for the 2050s of all 17 available GCMs, which is considered as a good representation for use in spatial studies (Tebaldi and Knutti, 2010). For the study area, a mean increase in annual precipitation of $61 \mathrm{~mm} \mathrm{yr}^{-1}$ $(+12 \%)$ is projected under this scenario, with highest values towards the north-west (up to $180 \mathrm{~mm}$ increase, Fig. 3d). An area average mean warming of $2.7^{\circ} \mathrm{C}$ is also projected. WaterWorld uses the monthly temperature and precipitation grids from the IPCC SRES GCM data, downscaled to $1 \mathrm{~km}$ spatial resolution by CCAFS (Ramirez and Jarvis, 2008) using the delta method to drive the scenario hydrology. Processes of snowfall and snowmelt, fog and fog water interception, rainfall and evapotranspiration respond to these climatic forcings.

\subsubsection{Population growth}

Population growth was simulated in the model by applying the WaterWorld population scenario generator (Mulligan et al., 2013). The population scenario generator calculates a rate of change based on the IPCC SRES scenarios for years 1990 to 2100 and applies these deltas to the population data set used for the baseline (Landscan, 2007). Here we apply the SRES rates of change up to 2050. This results in an increase in population of nearly $45 \%$ throughout the region, mostly around current population centres, with greatest increase in the Andean subbasins (Fig. 3e) The population increase under this scenario agrees with current reported population growth rates in the region (Perz et al., 2010; Cardozo, 2011).

\subsubsection{The combined scenario}

Our combined scenario "stacks" a series of independently generated scenarios, where we can we try to ensure consistency between scenarios (for example using the SRES scenarios for both climate change and population growth). This is not always possible since the links between scenarios, for example interactions between oil development and associated agricultural development, are not consistent. Historically oil development has led to improved access and thus enhanced agricultural development, but that is not always the case and there are many example of oil roads which lead to little immigration and agricultural development. The key focus in the development of the combined scenario is to ensure that each individual scenario is plausible given recent developments in the region. 

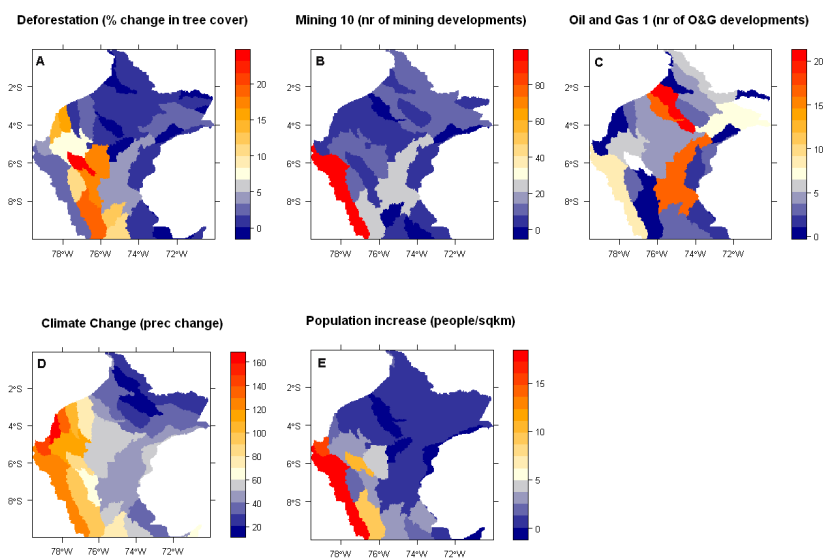

Fig. 3. (a)-(e) Key changes for 5 individual scenarios by major subbasin (HydroSHEDS). (a) \% change in tree cover based on WaterWorld land use model for 2050s. (b) Number of mining developments if $10 \%$ of current concessions get converted. (c) Number of oil and gas developments if $1 \%$ of current concessions get converted. (d) Precipitation change for mean of 17 GCM under A2A scenario for 2050s. (e) Population increase based on SRES projections for 2050s.
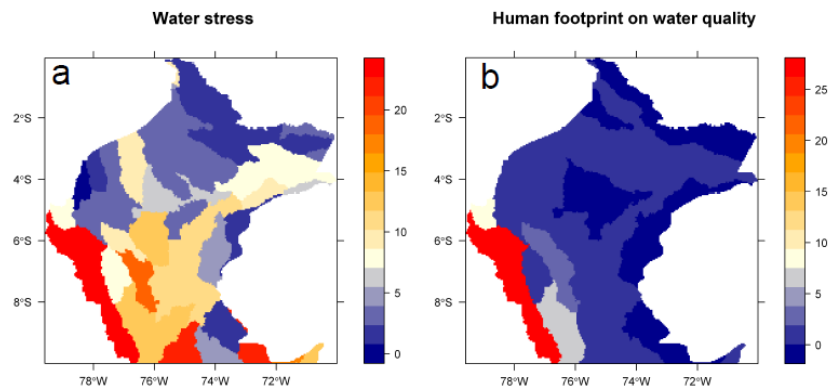

Fig. 4. (a) Baseline annual average water stress (\%) and (b) human footprint on water quality index (HF) averaged over major subbasin (HydroSHEDS) classes (\%).

\section{Results and discussion}

\subsection{Baseline water security}

The baseline assesses the current situation based on long-term climatic data (1950-2000) and current land cover (2010). Figure 4a shows the WaterWorld simulated baseline water stress index by major subbasin (HydroSHEDS), defined as the percentage of industrial and domestic (blue water) demand not supplied in months at which supply $<$ demand averaged across the year.

The water stress index shows that towards the south-west of the study region and particularly in the Andean Basin up to $20 \%$ of the demand cannot be met climatically, which means these areas depend on water storage or transfer during parts or all of the year. Further north and thus further into the Amazon rainforest, demand is met climatically for nearly every
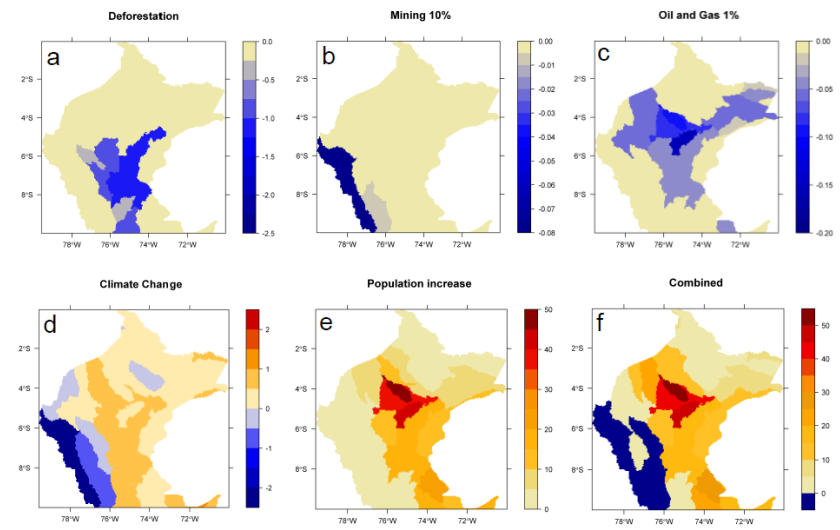

Fig. 5. (a)-(f) Change in water stress index averaged over major subbasin (HydroSHEDS) for scenarios of change, \% of nonagricultural (blue water) demand not supplied in months at which supply $<$ demand across the year.

month. Figure $4 \mathrm{~b}$ shows the human footprint on water quality, with the Andean highlands clearly most impacted.

\subsection{Changes to water security}

Figure 5 shows the WaterWorld-simulated changes in water stress by major subbasin, and Fig. 6 shows the changes in the human footprint on water quality index for all 5 individual scenarios as well as a combined scenario.

\subsubsection{Deforestation}

Under a scenario of deforestation where forest is converted to pasture, there are increases in available water since short herbaceous cover has lower evapotranspiration than the trees it replaces. This results in minor decreases in water stress ( $\max -1 \%$ ), with the greatest change in those subbasins where most of the deforestation has taken place (Figs. $2 b$ and $3 \mathrm{a}$ ). The changes in water quantity are minor because there is relatively little difference in AET between the cover types and the changes in resulting water balance tend not to affect the stress index significantly since AET is often much lower than precipitation for this region. The change in the human footprint on water quality index under this scenario (as shown in Fig. 6a) is minor, with some relatively small increases in water quality in some of the basins affected by deforestation as a result of increased runoff due to decreased water use by forest and therefore more dilution of contamination. Overall, land use change projections that might be expected in the next $50 \mathrm{yr}$ lead to only small effects on water quantity and water quality. The resulting impacts on people's exposure to water stress are therefore minor.

\subsubsection{Mining in $10 \%$ of concession}

Development of $10 \%$ of the mining concessions in the region leads to a clearing of forest cover and thus a decrease 

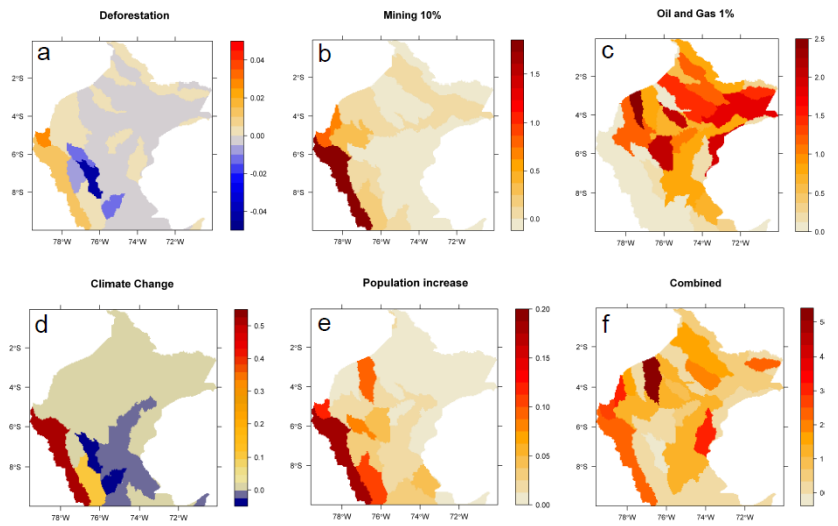

Fig. 6. (a)-(f) Change in human footprint on water quality index averaged over major subbasin (HydroSHEDS) classes (\%) for scenarios of change. Negatives (decreases in human footprint) in blue.

in AET which results in a localised decrease in water stress. From Fig. 5 it can be seen that the extent of the impact on water stress for this scenario is minor with only a few major subbasins impacted as a result of the implementation of this scenario within the mining concessions that are centred around the Andean highlands. A more sophisticated rule that clusters around existing mines or roads is possible, but the simplest case was used here. This scenario has a relatively large impact on water quality with a significant increase in the human footprint on water quality index in the Andean highlands. It is these regions where most current mining and concessions are, and it is likely that future developments will focus on these areas first.

\subsubsection{Oil and gas in $1 \%$ of the concession}

Similar to the results on the development of mines, a scenario whereby oil and gas extraction is developed on $1 \%$ of all land covered by oil and gas concessions in the study area leads to an increase in the water budget as a result of decreases in AET. This leads to a decrease in water stress. The impacts are minimal though, with most basins only showing a very minor decrease. In terms of water quality, changes in the HF index are much more pronounced. Since the oil and gas concessions are spatially distributed throughout the entire Peruvian Amazon lowlands, almost all major subbasins are impacted. Clearly if mining or o\&g were responsible for highly toxic emissions compared with other land uses, then the impacts of these on acceptable water quality would transfer very far downstream. Local-scale impacts at or downstream of the new developments can be significant, but since these are relatively small developments within large subbasins, the impacts are thus less apparent at the basin scale.

\subsubsection{Climate change}

The multi-model climate change scenario shows a much greater impact on water stress because it projects significant increases in precipitation over large areas. However, increased temperature also leads to higher evapotranspiration rates, which means the mean overall water stress shows increases in some subbasins (mainly in the Amazon lowlands) and decreases in others (mainly in the Andean highlands). This is the result of the spatial variability of the temperature in the region, resulting in much lower AET in the Andean highlands as well as the variability in precipitation projection between highlands and lowlands. Water quality changes as a result of climate change are minimal as there is no associated change in pollution sources. Changes in the seasonal distribution of precipitation could drive changes in human land use to decrease water quality, though these effects are too complex and uncertain to be incorporated in this analysis. Water quality issues could also result from changes to the frequency and magnitude of extreme events projected for the future (IPCC, 2012). Such events are extremely difficult to model though, and since WaterWorld, as a water resource model, uses a monthly time step, such impacts cannot be quantified. It also should be noted that there is significant uncertainty in GCM climate projections, particularly for rainfall and especially in heterogeneous environments such as the Andes (e.g. Buytaert et al., 2009), where often there is not even agreement on the sign of change between GCMs. While we identify a representative estimator by applying a scenario using the mean of all GCMs as a measure of the central tendency of the projections, using single GCMs or different combinations of GCMs could lead to very different results.

\subsubsection{Population growth}

A scenario of population growth based on the SRES growth projection rates extended to 2050 leads to change in water stress as a result of increased demand, most clearly in those subbasins where population is projected to increase most (see Fig. 3e). As well as impacts on water stress, the human footprint index on water quality changes considerably under this scenario. As is clear from Fig. 6e, nearly all subbasins see an increase in the human footprint on water quality index as a result of increased inputs of "brown" water (sewage) and "grey" water (waste water from irrigation, industrial processes and domestic use).

\subsubsection{The combined scenario}

When all the above scenarios are combined into one single scenario, water stress increases for most subbasins, mostly as a result of increased demand through population increase that leads to a greater increase in water stress than the small decreases resulting from extractives scenarios, deforestation and, for some subbasins, climate change. It is important to 
Table 1. Sensitivity to water stress (\% change in water stress per \% change in variable) as mean for Amazonian lowlands (AL) and Andean highlands $(\mathrm{AH})$.

\begin{tabular}{|c|c|c|c|c|c|c|c|c|c|c|c|c|}
\hline & \multicolumn{2}{|c|}{ Precipitation } & \multicolumn{2}{|c|}{ Temperature } & \multicolumn{2}{|c|}{ Tree cover } & \multicolumn{2}{|c|}{ Herb cover } & \multicolumn{2}{|c|}{ Bare cover } & \multicolumn{2}{|c|}{ Population } \\
\hline & $\mathrm{AL}$ & $\mathrm{AH}$ & AL & $\mathrm{AH}$ & $\mathrm{AL}$ & $\mathrm{AH}$ & $\mathrm{AL}$ & $\mathrm{AH}$ & $\mathrm{AL}$ & $\mathrm{AH}$ & $\mathrm{AL}$ & $\mathrm{AH}$ \\
\hline \multicolumn{13}{|l|}{ Scenario } \\
\hline Climate change & 2.2 & 6.23 & 0.01 & 0.16 & - & - & - & - & - & & - & - \\
\hline Deforestation & - & & - & - & 0.08 & 0.01 & 0.08 & 0.01 & 0.98 & 0.12 & - & - \\
\hline Mining & - & & - & - & 0.04 & 0.34 & 0.03 & 0.03 & 0.01 & 0.03 & - & - \\
\hline $\mathrm{O} \& \mathrm{G}$ & - & & - & - & 0.03 & 0.06 & 0.1 & 0.03 & 0.02 & 0.03 & - & - \\
\hline Population & - & & - & - & - & - & - & - & - & - & 22.9 & 1.02 \\
\hline Combined & 60.5 & 11.0 & 0.52 & 0.34 & 0.13 & 0.02 & 0.22 & 0.24 & 1.28 & 0.24 & 22.9 & 1.0 \\
\hline
\end{tabular}

note here that we do not examine the impact of changed climate on vegetation growth and cover and thus the potential of a drying climate to reduce vegetation cover and thus evapotranspiration, offsetting some of the effects on water balance (but also potentially reducing rainfall inputs). Climate change can have a significant impact upon water stress, but the uncertainty in climate change projections makes it difficult to develop adaptation strategies to mitigate these impacts. In terms of water quality, the mining, oil and gas and population growth scenarios, and to a lesser extent the climate change scenario, have the greatest impact on the human footprint on water quality index. With such a large area of the region under mining and oil and gas concessions, strict management and regulation of development and its cascading impacts will be essential to protect the region from serious environmental and water resource degradation.

\subsection{Sensitivity analysis}

In order to assess the sensitivity of the water stress and human footprint on water quality metrics to change in drivers, a sensitivity test was carried out that explores the relative change in water stress (Table 1) and HF index (Table 2) per unit change of each key variable on a pixel basis. This is repeated for each scenario for the Andean highlands and the Amazonian lowlands regions separately (see Fig. 1). Water stress is, as expected, most sensitive to change in precipitation as a result of climate change and to population, with changes in the latter having a far greater impact, particularly in the Amazonian lowlands. Sensitivity of water stress to precipitation is greater in the Andean highlands where water demand is higher (Fig. 4d). Sensitivity of water stress to land use changes as a result of deforestation and extractives development is generally low. This reflects both the much lower impact of evapotranspiration changes on water stress (compared with rainfall changes) and the fact that land use changes tend to occur in areas with currently lower population.

In contrast with the water stress indicator, the human footprint on water quality index is more sensitive to changes in land cover as a result of extractive development than for deforestation. Since the deforestation scenario converts areas near existing deforestation fronts and major towns first, many pixels in these areas are already partly converted, whereas the extractive scenarios are more implemented in "pristine", fully forested areas leading to greater sensitivity of HF to conversion.

While this analysis has captured the most pertinent threats to long-term water security in the region, some threats from major infrastructure such as scenarios for building of dams have not been included. Currently there are 6 large dams in the study area (Mulligan, 2011), but there are plans for the development of a further 39 large dams (Finer and Jenkins, 2012). The development of these dams may drive deforestation as a result of road building, transmission lines and displacement associated with inundation. New dams have the potential to increase water security through their storage potential but are also themselves at risk from sedimentation which could be accelerated by upstream developments such as urbanisation and extractives development - and climate change. This could have serious implications for water quantity and water quality downstream due to changes in managed flow regulation and changes in sediment loads. Limited information is available on groundwater utilisation in the study region. Although McClain et al. (2001) found that in rural areas of the central Peruvian Amazon groundwater is used for human consumption (up to $18 \%$ from wells), ground water use in the more populated Andean highlands is likely to be small given the difficulty of extracting it as a result of the complex geology (Buytaert et al., 2006). Utilisation of groundwater resources can potentially offset water security impacts in the short term. However, when water balance is reduced, groundwater reserves are diminished and thus groundwater cannot resolve insecurity in the long term, which is primarily determined by water supply (water balance) vs. water demand. Groundwater depletion is already occurring in even very large groundwater systems around the world (Aeschbach-Hertig and Gleeson, 2012).

WaterWorld has been used to identify those areas that are under greatest water security threat from multiple factors. 
Table 2. Sensitivity to human footprint on water quality index (\% change in HF value per $\% 7$ change in variable) as mean for Amazonian lowlands (AL) and Andean highlands (AH).

\begin{tabular}{|c|c|c|c|c|c|c|c|c|c|c|c|c|}
\hline & \multicolumn{2}{|c|}{ Precipitation } & \multicolumn{2}{|c|}{ Temperature } & \multicolumn{2}{|c|}{ Tree cover } & \multicolumn{2}{|c|}{ Herb cover } & \multicolumn{2}{|c|}{ Bare cover } & \multicolumn{2}{|c|}{ Population } \\
\hline & $\mathrm{AL}$ & $\mathrm{AH}$ & $\mathrm{AL}$ & $\mathrm{AH}$ & $\mathrm{AL}$ & $\mathrm{AH}$ & $\mathrm{AL}$ & $\mathrm{AH}$ & $\mathrm{AL}$ & $\mathrm{AH}$ & $\mathrm{AL}$ & $\mathrm{AH}$ \\
\hline \multicolumn{13}{|l|}{ Scenario } \\
\hline Climate change & 0.0 & 0.1 & 0.0 & 0.0 & - & - & - & - & - & - & - & - \\
\hline Deforestation & - & - & - & - & 0.0 & 0.0 & 0.0 & 0.0 & 0.0 & 0.01 & - & - \\
\hline Mining & - & - & - & - & 2.47 & 6.96 & 1.60 & 0.96 & 0.77 & 0.66 & - & - \\
\hline $\mathrm{O} \& \mathrm{G}$ & - & - & - & - & 1.18 & 1.75 & 4.26 & 3.68 & 0.89 & 0.91 & - & - \\
\hline Population & - & - & - & - & - & - & - & - & - & - & 1.44 & 0.13 \\
\hline Combined & 6.9 & 8.42 & 0.05 & 0.11 & 0.01 & 0.07 & 0.01 & 0.02 & 0.13 & 0.16 & 1.08 & 0.33 \\
\hline
\end{tabular}

This has been done by modelling individual scenarios and then a combined scenario of change. WaterWorld's built-in scenario generator allows for a rapid assessment of the impacts of many different scenarios relative to baseline conditions. Since the model includes all necessary data, nontechnical users can model their areas of interest and apply local knowledge in generating these scenarios, exploring a multitude of feedbacks between the hydrological system and human interventions within this system.

\section{Conclusions}

This paper has applied hydrological scenario modelling with the WaterWorld policy support system using globally available data. The system allows users without specific technical or hydrological capacity to explore the hydrological baseline and potential impacts of scenarios of change for anywhere in the world. Here we have carried out an assessment of multiple threats to water security in the Peruvian Amazon. The results show the threats to water security from decreased water quality as current deforestation and population growth continue and if $10 \%$ of all mining and $1 \%$ of all oil and gas concessions in the region were to be developed. Whilst individual drivers of change have geographically variable effects, the combined effect both is more relevant to real futures and shows evidence of different drivers exacerbating or reducing the impact of others according to their relative magnitudes and geographical footprints in relation to the areas of greatest water demand. An increase in population is the main driver for increased water stress and decreased water quality, while climate change has the potential to exacerbate or cancel out some of the land-based threats. Deforestation either for agriculture or as a result of extractive development has a relatively small impact on water stress compared to changes in climate or population at the basin level. Therefore, water stress is likely to increase in those highly concentrated areas where population is expected to grow rapidly, even in the absence of other developments impacting water availability such as deforestation and extractives development. However, impacts on water quality as a result of extractive development will be highly concentrated. The impacts of climate change are hugely uncertain because of uncertainty in the magnitude and even direction of rainfall change at these scales, whereas the scenarios for population growth have greater certainty. It is critical for analyses of the water resource impact of land use change or climate change to take account of this climate uncertainty but also to understand climate change within the context of multiple other threats to water quantity and quality in the region. If these multiple threats occur at the same timescale as climate change, then their interaction with climate change cannot be ignored but will not always be negative from a water security perspective.

In order for tools such as WaterWorld to be useful in the decision making process, it is important that uncertainties and model assumptions are communicated effectively. WaterWorld allows for exploring a wide range of scenarios and uncertainties (e.g. by including the full range of climate change models and by providing alternative data sets for baseline variables such as rainfall). The system also provides tools for spatial sensitivity analysis of scenarios of change. Furthermore, different interfaces to the model restrict functionality and present results in more simple and generalised ways for non-experts. Given the inherent uncertainty in scenario projections and model outputs, it is important for decision makers to be aware of the range of possible outcomes as well as to consider no-regrets options to adaptation. Specific adaptation pathways cannot be adopted given the very high degree of uncertainty associated with the key hydrological driver (rainfall change), so it is better to focus on preparedness and adaptability whilst managing the scenarios (land use, mining, oil and gas) that regional policy makers have some control over. While the identified levels of water stress at the basin level as determined in this analysis give a good first-order estimation of areas of concern, actual water stress by different sectors and social groups is not identified here. Projections of water stress in basins do not represent the realities at finer scales where socio-economically defined access to water rather than biophysically defined availability of water is critical. Additional analysis using social, political and economic data sets would be required to address these issues. 
Acknowledgements. The WaterWorld model has been developed over a number of research projects from DESURVEY, BFPANDES, and COMPANDES and in collaboration with a range of global data providers. This analysis takes from the CDKN-funded report of Mulligan et al. (2013) commissioned by GCP and CIAT.

Edited by: M. Sivapalan

\section{References}

Aeschbach-Hertig, W. and Gleeson, T.: Regional strategies for the accelerating global problem of groundwater depletion, Nat. Geosci., 5, 853-861, 2012.

Bakker, K.: Water security: research challenges and opportunities, Science, 337, 914-915, 2012.

Bebbington, A. J. and Bury, J. T.: Institutional challenges for mining and sustainability in Peru, Proc. Natl. Acad. Sci., 106, 1729617301, 2008.

Braga, B., Varella, P., and Concalves, H.: Transboundary water management of the Amazon basin, Int. J. Water Resour. Develop., 27, 477-496, 2011.

Bruijnzeel, L. A., Mulligan, M., and Scatena, F. N.: Hydrometeorology of tropical montane cloud forests: emerging patterns, Hydrol. Process., 25, 465-498, 2011.

Buytaert, W., Célleri, R., De Bievre, B., Cisneros, F., Wyseure, G., Deckers, J., and Hofstede, R.: Human impact on the hydrology of the Andean páramos, Earth Sci. Rev., 79, 53-72, 2006.

Buytaert, W., Celleri, R., and Timbe, L.: Predicting climate change impacts on water resources in the tropical Andes: effects of GCM uncertainty, Geophys. Res. Lett., 36, L07406, doi:10.1029/2008GL037048, 2009.

Cardozo, M.: Economic displacement and local attitude towards protected area establishment in the Peruvian Amazon, Geoforum, 42, 603-614, 2011.

Casimiro, W. S. L., Labat, D., Guyot, J. L., and Ardoin-Bardin, S.: Assessment of climate change impacts on the hydrology of the Peruvian Amazon-Andes basin, Hydrol. Process., 25, 37213734, 2011.

Casimiro, W. S. L., Ronchail, J., Labat, D., Espinoza, J. C., and Guyot, J. L.: Basin-scale analysis of rainfall and runoff in Peru (1969-2004): Pacific, Titicaca and Amazonas drainages, Hydrol. Sci. J., 57, 1-18, doi:10.1080/02626667.2012.672985, 2012.

Cook, C. and Bakker, K.: Water security: debating an emerging paradigm, Global Environ. Change, 22, 94-102, 2012.

DeFries, R. S., Rudel, T. Uriarte, M., and Hansen, M.: Deforestation driven by urban population growth and agricultural trade in the twenty-first century, Nat. Geosci., 3, 178-181, 2010.

Finer, M. and Jenkins, C. N.: Proliferation of hydroelectric dams in the Andean Amazon and implications for Andes-Amazon connectivity, PloS One, 7, e35126, doi:10.1371/journal.pone.0035126, 2012.

Finer, M. and Orta-Martinez, M.: A second hydrocarbon boom threatens the Peruvian Amazon: trends, projections, and policy implications, Environ. Res. Lett., 5, 014012, doi:doi:10.1088/1748-9326/5/1/014012, 2010.

Gleick, P. H. and Palaniappan, M.: Peak water limits to freshwater withdrawal and use, Proc. Natl. Acad. Sci. USA, 107, 11155$11162,2010$.
Guimberteau, M., Ronchail, J., Espinoza, J. C., Lengaigne, M., Sultan, B., Polcher, J., Drapeau, G., Guyot, J. L., Ducharne, A., and Ciais, P.: Future changes in precipitation and impacts on extreme streamflow over Amazonian sub-basins, Environ. Res. Lett., 8, 014035, doi:10.1088/1748-9326/8/1/014035, 2013.

Hansen, M., DeFries, R., Townshend, J. R., Caroll, M., Dimiceli, C., and Sohlberg, R.: Vegetation continuous fields MOD44B, 2001 Percent Tree Cover, Collection 4, University of Maryland, College Park, Maryland, 2006.

Hijmans, R. J., Cameron, S. E., Parra, J. L., Jones, P. G., and Jarvis, A.: Very high resolution interpolated climate surfaces for global land areas, Int. J. Climatol., 25, 1965-1978, 2005.

Hope, R., Hansen, K., Mutembwa, M., and Schlessinger, S.: Water security, risk and society - key issues and research priorities for international development. Synthesis report submitted to UK collaborative on development sciences by Oxford University Water Security Network, 2012.

IPCC: Managing the risks of extreme events and disasters to advance climate change adaptation: a special report of working groups I and II of the Intergovernmental Panel on Climate Change, edited by: Field, C. B., Barros, V., Stocker, T. F., Qin, D., Dokken, D. J., Ebi, K. L., Mastrandrea, M. D., Mach, K. J., Plattner, G.-K., Allen, S. K., Tignor, M., and Midgley, P. M., Cambridge, UK, and New York, NY, USA, 582 pp., 2012.

IUCN and UNEP: The World Database on Protected Areas (WDPA) UNEP-WCMC, Cambridge, UK, 2009.

Marengo, J. A.: On the hydrological cycle of the Amazon basin: a historical review and current state-of-the-art, Rev. Bras. Meteorol., 21, 1-19, 2006.

McClain, M. E., Aparicio, L. M., and Llerena, C. A.: Water use and protection in rural communities of the Peruvian Amazon basin, Water Int., 26, 400-410, 2001.

Mulligan, M.: The human water quality footprint: agricultural, industrial and urban impacts on the quality of available water globally and in the Andean region, Proceedings of the International Conference on Integrated Water Resource Management and Climate Change, Cali, Colombia, 11 pp., 2009.

Mulligan, M.: Simterra: a consistent global gridded database of environmental properties for spatial modelling, available at: http:// www.policysupport.org/simterra, last access: 14 December 2013 , [based on multiple sources], 2011.

Mulligan, M.: WaterWorld v2.x documentation, available at: http: //www.policysupport.org/waterworld (last access: 14 December 2013), 2013a.

Mulligan, M.: WaterWorld: a self-parameterising, physicallybased model for application in data-poor but problemrich environments globally, Hydrol. Res., 44, 748-769, doi:10.2166/nh.2012.217, 2013b.

Mulligan, M. and Burke, S.: FIESTA Fog Interception for the Enhancement of Streamflow in Tropical Areas. Final technical report for AMBIOTEK contribution to DFID FRP R7991, 2005.

Mulligan, M. Saenz-Cruz, L., van Soesbergen, A., Smith, V. T., and Zurita, L.: Global dams database and geowiki, Version 1, available at: http://geodata.policysupport.org/dams (last access: 14 December 2013), 2009. 
Mulligan, M., Rubiano, J., Burke, S., and Van Soesbergen, A.: Water security in Amazonia. Report for Global Canopy Programme and International Center for Tropical Agriculture as part of the Amazonia Security Agenda project, available at: http://segamazonia.org, last access: 14 December 2013.

Nakicenovic, N., Alcamo, J., Davis, G., de Vries, B., Fenhann, J., Gaffin, S., Gregory, K., Grubler, A., Jung, T. Y., Kram, T., Emilio la Rovere, E., Michaelis, L., Mori, S., Morita, T., Pepper, W., Pitcher, H., Price, L., Riahi, K., Roerhl, A., Rogner, H. H., Sankovski, A., Schlesinger, M., Shukla, P., Smith, S., Swart, R., Van Rooyen, S., Victor, N., and Dadi, Z. (Eds.): Special report on emissions scenarios, Cambridge University Press, Cambridge, 2000.

Napolitano, D. A. and Ryan, A. S. S.: The dilemma of contact: voluntary isolation and the impacts of gas exploitation on health and rights in the Kugapakori Nahua Reserve, Peruvian Amazon, Environ. Res. Lett., 2, 045005, doi:10.1088/1748-9326/2/4/045005, 2007

Orta-Martínez, M., Napolitano, D. A., MacLennan, G. J., O'Callaghan, C., Ciberowski, S., and Fabregas, X.: Impacts of petroleum activities for the Achuar people of the Peruvian Amazon: summary of existing evidence and research gaps, Environ. Res. Lett., 2, 045006, doi:10.1088/1748-9326/2/4/045006, 2007.

Perz, S. G., Cabrera, L., Carvalho, L. A., Castillo, J., and Barnes, G.: Global economic integration and local community resilience: road paving and rural demographic change in the Southwestern Amazon, Rural Soc., 75, 300-325, 2010.

Postel, S. L. and Wolf, A. T.: Dehydrating conflict, Foreign Pol., 126, 60-67, 2001.

Ramankutty, N., Evan, A. T., Monfreda, C., and Foley, J. A.: Farming the planet: 1. Geographic distribution of global agricultural lands in the year 2000, Global Biochem. Cy., 22, 1-19, 2008.

Ramirez, J. and Jarvis, A.: High resolution statistically downscaled future climate surfaces, International Centre for Tropical Agriculture CIAT, 2008.

Rockström, J., Steffen, W., Noone, K., Persson, A., Chapin, F., Lambin, E., Lenton, T., Scheffer, M., Folke, C., Schellnhuber, H., Nykvist, B., De Wit, C., Hughes, T., van der Leeuw, S., Rodhe, H., Sorlin, S., Snyder, P., Costanza, R., Svedin, U., Falkenmark, M., Karlberg, L., Corell, R., Fabry, V., Hansen, J., Walker, B., Liverman, D., Richardson, K., Crutzen, P., and Foley, J.: Planetary Boundaries: Exploring the Safe Operating Space for $\mathrm{Hu}-$ manity, Ecol. Soc., 14, 32, 2009.
Sivapalan, M., Blöschl, G., Zhang, L., and Vertessy, R.: Downward approach to hydrological prediction, Hydrol. Process., 17, 21012111, doi:10.1002/hyp.1425, 2003.

Swenson, J. J., Carter, C. E., Domec, J. C., and Delgado, C. I.: Gold mining in the Peruvian Amazon: global prices, deforestation, and Mercury imports, PloS ONE, 6, e18875, doi:10.1371/journal.pone.0018875, 2011.

Tebaldi, C. and Knutti, R.: Climate models and their projections of future changes, in: Climate change and food security: adapting agriculture to a warmer world, Vol. 37, edited by: Lobell, D. B. and Burke, M., Springer, 2010.

Thornes, J. B.: The interaction of erosional and vegetational dynamics in land degradation: spatial outcomes, John Wiley and Sons, Ltd, New York, 1990.

Van Soesbergen, A. J. J.: Impacts of climate change on water resources of global dams, Ph.D. Thesis, King's College London, 2013.

Vörösmarty, C. J., McIntyre, P. B., Gessner, M. O., Dudgeon, D., Prusevich, A., Green, P., Glidden, S., Bunn, S. E., Sullivan, C. A., Reidy Liermann, C., and Davies, P. M.: Global threats to human water security and river biodiversity, Nature, 467, 555-561, 2010 .

Wagener, T., Sivapalan, M., Troch, P., McGlynn, B., Harman, C., Gupta, H., Kumar, P., Rao, P. S., Basu, N., and Wilson, J.: The future of hydrology: An evolving science for a changing world, Water Resour. Res., 46, W05301, doi:10.1029/2009WR008906, 2010 .

Walter, M. T., Brooks, E. S., McCool, D. K., King, L. G., Molnau, M., and Boll, J.: Process based snowmelt modelling: does it require more input data than temperature index modelling?, J. Hydrol., 300, 65-75, 2005.

Weinhold, D. and Reis, E. J.: Model evaluation and causality testing in short panels: the case of infrastructure provision and population growth in the Brazilian Amazon, J. Reg. Sci., 41, 639-658, 2001.

Yates, D., Sieber, J., Purkey, D., and Huber-Lee, A.: WEAP21 A Demand-, Priority-, and Preference-Driven Water Planning Model: Part 1: Model Characteristics, Water Int., 30, 487-500, 2005.

Zuritha-Arthos, L. and Mulligan, M.: Multi-Criteria GIS Analysis and Geo-Visualisation of the Overlap of Oil Impacts and Ecosystem Services in the Western Amazon, Int. J. Geoinf., 9, 45-52, 2013. 